\title{
Electrocatalytic Hydrogen Evolution and Oxygen Reduction on Polyoxotungstates/Graphene Nanocomposite Multilayers
}

\author{
Min Jiang, ${ }^{\dagger}$ Dandan Zhu, ${ }^{\dagger}$ Jinjun Cai, ${ }^{\dagger}$ Hongyu Zhang, ${ }^{*}{ }^{\ddagger}$ and Xuebo Zhao*, ${ }^{\dagger}$ \\ ${ }^{\dagger}$ Applied Energy Center, Qingdao Institute of Bioenergy and Bioprocess Technology, Chinese Academy of Sciences, Qingdao, \\ 266101, P. R. China \\ ${ }^{\ddagger}$ College of Chemistry and Chemical Engineering, Ocean University of China, Qingdao 266100, P. R. China
}

Supporting Information

ABSTRACT: Negatively charged Pressler-type heteropolytungstate $\mathrm{K}_{12.5} \mathrm{Na}_{1.5}\left[\mathrm{NaP}_{5} \mathrm{~W}_{30} \mathrm{O}_{110}\right]\left(\mathrm{P}_{5} \mathrm{~W}_{30}\right)$ clusters and graphene oxide (GO) were constructed into polyoxotungstates/graphene (POTs/G) nanocomposite multilayer with protonated poly(ethylenimine) (PEI) via layer-by-layer self-assembly. The growth process of (PEI/ $\left.\mathrm{P}_{5} \mathrm{~W}_{30}-\mathrm{GO}\right)_{n}$ multilayer films was monitored by UV-visible spectroscopy and cyclic voltammetry. The atomic force microscopy images clearly showed the morphology of single-sheet GO in multilayer films. The UV-light irradiation of multilayers afforded reduced graphene oxide (RGO) in the multilayers. The changes in composition of $\mathrm{C} 1 \mathrm{~s}$ in

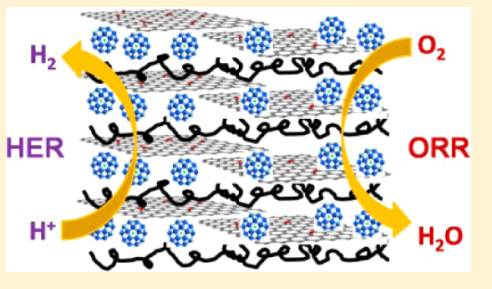
$\mathrm{GO}, \mathrm{W} 4 \mathrm{f}$ in $\mathrm{P}_{5} \mathrm{~W}_{30}$, and $\mathrm{N}$ 1s in PEI were detected by X-ray photoelectron spectroscopy. A possible photoreduction mechanism of $\mathrm{GO}$ was proposed. The electrochemical behavior of $\left(\mathrm{PEI} / \mathrm{P}_{5} \mathrm{~W}_{30}-\mathrm{RGO}\right)_{n}$ multilayers modified on a glassy carbon electrode at room temperature and their electrocatalytic activity toward oxygen reduction reaction (ORR) and hydrogen evolution reaction (HER) were investigated. At a potential of $-0.6 \mathrm{~V}$, the multilayers clearly exhibited electrocatalytic activity for ORR via almost a four-electron reduction pathway to $\mathrm{H}_{2} \mathrm{O}$. A remarkable electrocatalytic $\mathrm{HER}$ could be detected on the $\left(\mathrm{PEI} / \mathrm{P}_{5} \mathrm{~W}_{30}-\mathrm{RGO}\right)_{n}$ multilayer, whereas the $\left(\mathrm{PEI} / \mathrm{P}_{5} \mathrm{~W}_{30}-\mathrm{GO}\right)_{n}$ multilayer did not show any HER signal in the same potential range. This study investigated and extended the application of POTs/G nanocomposites to the electrocatalysis of ORR and HER.

\section{INTRODUCTION}

Graphene has stimulated a large amount of research in the past decade owing to its unique characteristics such as large specific surface area, excellent electrical conductivity, and great mechanical strength. ${ }^{1}$ These advantages make graphene a very promising candidate for immobilizing functional molecules. $^{2}$ On one hand, functional molecules can be uniformly dispersed by the adsorption on graphene. On the other hand, some of the properties of functional molecules can be significantly improved by adsorbing them onto a graphene support. At present, metals, ${ }^{3}$ noble metals, ${ }^{4}$ polymers, ${ }^{5}$ semiconductors, ${ }^{6}$ inorganic nanoparticles, ${ }^{7}$ and enzymes ${ }^{8}$ have been used to construct graphene-based hybrid composites, which have been widely used in various fields, including supercapacitors, ${ }^{5}$ biosensors, ${ }^{9}$ photocatalysts, ${ }^{6}$ electrocatalysts, ${ }^{10}$ and lithium-ion batteries. ${ }^{11}$ Polyoxotungstates (POTs) are well-organized tungsten-oxygen clusters with diverse sizes, nuclearities, and shapes. They are the main members of the polyoxometalates (POMs) family and have a higher chemical stability than the other types of POMs. ${ }^{12}$ As versatile inorganic entities for the construction of functional materials, POTs have been widely used in photocatalysis and electrocatalysis. ${ }^{13-16}$ POTs/graphene (POTs/G) composites may significantly improve the catalytic properties of POTs and even offer new applications of these hybrid materials. In fact, such an idea primarily originated from the study on the preparation of graphite oxide/POMs. ${ }^{17,18}$ The preparation and investigation of POMs/G composites is very recent and gradually expanding from the first report in 2010. ${ }^{19-29}$ Zhou et al. synthesized phosphomolybdic acid/graphene composites using hydrazine hydrate in order to reduce a mixture of phosphomolybdic acid and graphene oxide (GO) solution. ${ }^{19} \mathrm{Li}$ et al. developed a photoreduction method to obtain graphene sheets using $\mathrm{H}_{3} \mathrm{PW}_{12} \mathrm{O}_{40}\left(\mathrm{PW}_{12}\right)$ as the stabilizer in isopropanol. ${ }^{20}$ Later, they combined layer-by-layer (LbL) self-assembly ${ }^{30}$ and in situ photoreduction procedures to produce $\mathrm{PW}_{12} /$ graphene multilayers. $^{21}$ Rodriguez-Albelo et al. reported a new insoluble polyoxomolybdate with a four-coordination network based on the $\left\{\varepsilon\right.$ - $\left.\mathrm{PMo}{ }_{8} \mathrm{Mo}^{\mathrm{VI}}{ }_{4} \mathrm{O}_{40}(\mathrm{OH})_{4} \mathrm{Zn}_{4}\right\}$ and used it as the reducing agent to obtain polyoxomolybdate-immobilized graphene in pure water by continuously stirring for $6 \mathrm{~h}$ at room temperature. $^{22}$ Guo et al. immersed a graphene-modified electrode into a Ru-POT aqueous solution and obtained a stable Ru-POT/G electrocatalyst layer after washing and drying. ${ }^{25}$ Tessonnier et al. $^{28}$ and Kim et al. ${ }^{26}$ reported the preparation of POTs/G complexes by directly mixing graphene and POTs. Both $\mathrm{Li}$ et $\mathrm{al}^{27}$ and Wang et al. ${ }^{29}$ reported an electrochemical method for the synthesis of POTs/G composites by reducing GO with electron-rich POTs. These studies investigated the properties of POMs/G as the microelectrodes for photodetector devices, ${ }^{21}$ sensors to detect $\mathrm{H}_{2} \mathrm{O}_{2}{ }^{23}$ catalysts for water oxidation, ${ }^{25}$ and methanol

Received: March 27, 2014

Revised: $\quad$ May 18, 2014

Published: June 10, 2014 

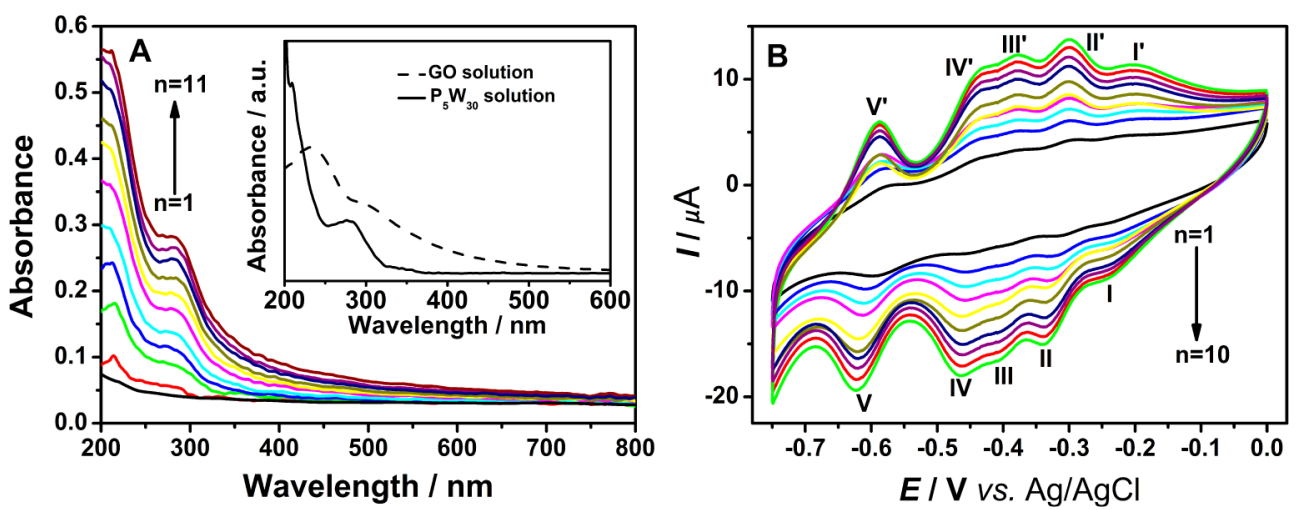

Figure 1. (A) UV-visible spectra of (PEI/ $\left.\mathrm{P}_{5} \mathrm{~W}_{30}-\mathrm{GO}\right)_{n}$ multilayer films with $n=1-11$ on quartz substrates (both sides). These curves, from bottom to top, correspond to $n=1-11$, respectively. The inset shows the UV-visible spectra of $0.5 \mathrm{mg} / \mathrm{mL}_{5} \mathrm{~W}_{30}$ solution (solid line) and $0.5 \mathrm{mg} /$ $\mathrm{mL}$ GO dispersion (dashed line). (B) Cyclic voltammograms of a GCE modified with (PEI/ $\left.\mathrm{P}_{5} \mathrm{~W}_{30}-\mathrm{GO}\right)_{n}$ multilayers (curves from inside to outside: $n=1-10)$ in $5 \times 10^{-3} \mathrm{~mol} / \mathrm{L} \mathrm{HCl}$ at a scan rate of $50 \mathrm{mV} / \mathrm{s}$.

oxidation. ${ }^{31}$ However, there is no report on the development of POTs/G electrocatalysts for oxygen reduction reaction $(\mathrm{ORR})^{32}$ and hydrogen evolution reaction (HER). ${ }^{33}$ An effective and less expensive electrocatalyst for ORR is a critical component for accelerating the widespread commercialization of proton exchange membrane fuel cells. An electrocatalyst with a lower HER overpotential will benefit hydrogen production for the comprehensive utilization of clean energy. Therefore, it is extremely attractive to extend the application of POTs/G composites to the electrocatalysis of ORR and HER.

For investigating the electrocatalytic behavior toward ORR and HER, POTs/G nanocomposites should be uniformly modified onto an electrode surface in order to provide a highly effective catalytic interface. Therefore, LbL self-assembly is regarded as the optimal method to fabricate uniform POTs/G thin films on electrodes. Herein, a two-step method involving LbL self-assembly and postphotoreduction was used to prepare POTs/G multilayers in this study. Pressler-type POT $\mathrm{K}_{12.5} \mathrm{Na}_{1.5}\left[\mathrm{NaP}_{5} \mathrm{~W}_{30} \mathrm{O}_{110}\right]\left(\mathrm{P}_{5} \mathrm{~W}_{30}\right)$ clusters are extraordinarily stable toward hydrolysis at room temperature from $\mathrm{pH} 0$ to 11 and can respond to UV irradiation using protonized polyelectrolytes, $^{34}$ which may act as photocatalysts for the reduction of GO in the multilayers. To the best of our knowledge, this is the first report on the fabrication of $\mathrm{P}_{5} \mathrm{~W}_{30} / \mathrm{G}$ nanocomposites as well as their electrocatalytic application for ORR and HER.

\section{EXPERIMENTAL}

Materials. Graphite flakes and branched poly(ethylenimine) (PEI, MW 20000) were purchased from Aldrich. Other chemicals were purchased from Sinopharm Chemical Reagent Co. Ltd. Quartz slides and silicon wafer were commercially available. All the chemicals were reagent grade and used as received without further purification. The water used in all the experiments was deionized to a resistivity of $18 \mathrm{M} \Omega \mathrm{cm}$.

Preparation of $\mathrm{K}_{12.5} \mathrm{Na}_{1.5}\left[\mathrm{NaP}_{5} \mathrm{~W}_{30} \mathrm{O}_{110}\right]\left(\mathrm{P}_{5} \mathrm{~W}_{30}\right)$. In a typical experiment, ${ }^{35} 33 \mathrm{~g}$ of $\mathrm{Na}_{2} \mathrm{WO}_{4} \cdot 2 \mathrm{H}_{2} \mathrm{O}$ was dissolved in $30 \mathrm{~mL}$ of water, and $26.5 \mathrm{~mL}$ of $85 \% \mathrm{H}_{3} \mathrm{PO}_{4}$ was added. The mixture was placed in a Teflon-lined autoclave and heated at $120{ }^{\circ} \mathrm{C}$ for $12 \mathrm{~h}$. After the autoclave was cooled to room temperature, $15 \mathrm{~mL}$ of water and $10 \mathrm{~g}$ of $\mathrm{KCl}$ solid were added to the resulting yellow solution, affording a precipitate. The precipitate was filtered off and washed with $2 \mathrm{~mol} / \mathrm{L}$ potassium acetate and methanol. The collections were then redissolved in
$30 \mathrm{~mL}$ of hot water $\left(90^{\circ} \mathrm{C}\right)$. When the hot solution was cooled to room temperature, white crystals were formed. A second recrystallization afforded the pure product. $\operatorname{IR}(\mathrm{KBr}): 3374(\mathrm{~s})$, 1617(s), 1165 (s), 1080 (s), 1019 (m), 984 (m), 935 (s), 783 (s) $\mathrm{cm}^{-1}$.

Preparation of Graphene Oxide. GO was synthesized following Hummer's method by reacting natural graphite powder in a mixture of concentrated $\mathrm{H}_{2} \mathrm{SO}_{4}, \mathrm{NaNO}_{3}$, and $\mathrm{KMnO}_{4} \cdot{ }^{36}$ After the reaction was completed, $\mathrm{H}_{2} \mathrm{O}_{2}$ was added to the reaction vessel. $\mathrm{GO}$ was separated by centrifugation and washed twice with $1 \mathrm{~mol} / \mathrm{L} \mathrm{HCl}$ and 10 times with water. The product was dried in vacuum to afford brown sheets. GO dispersion was prepared by ultrasonically dissolving a required amount of GO solid into deionized water.

Multilayer Assembly. The multilayers were assembled on a quartz slide, silicon wafer, and glassy carbon electrode (GCE). The quartz slide was used for UV-visible spectroscopy measurement, and the silicon wafer was used for atomic force microscopy (AFM) and X-ray photoelectron spectroscopy (XPS). The GCE was used for electrochemical measurements. Quartz slides $\left(1 \times 2 \mathrm{~cm}^{2}\right)$ and silicon wafers $\left(1 \times 1 \mathrm{~cm}^{2}\right)$ were cleaned with a "piranha solution" at $80{ }^{\circ} \mathrm{C}$ for $30 \mathrm{~min}$, followed by washing with copious water. Further purification was carried out by immersing the substrates into a $\mathrm{NH}_{4} \mathrm{OH} / \mathrm{H}_{2} \mathrm{O}_{2} / \mathrm{H}_{2} \mathrm{O}=$ 1:1:5 (v/v) solution at $70{ }^{\circ} \mathrm{C}$ for $30 \mathrm{~min}$, followed by rinsing with copious water. Prior to the electrochemical modification, the GCE was successively polished with 0.3 and $0.05 \mathrm{~mm} \alpha$ $\mathrm{Al}_{2} \mathrm{O}_{3}$, ultrasonically washed with water between each experiment, and dried with $\mathrm{N}_{2}$.

Multilayer films were fabricated on the treated substrates by the sequential adsorption procedure reported in the literature. ${ }^{37}$ The substrates were first immersed in a PEI solution $(2 \mathrm{mg} /$ $\mathrm{mL}, \mathrm{pH} 7$ ) for $15 \mathrm{~min}$ to introduce positive charges onto the surface, rinsed with deionized water, and dried with $\mathrm{N}_{2}$. The PEI-coated substrates were then placed in a solution of $\mathrm{P}_{5} \mathrm{~W}_{30}$ $(1 \mathrm{mg} / \mathrm{mL})$ and $\mathrm{GO}(0.5 \mathrm{mg} / \mathrm{mL})$ with a $\mathrm{pH}$ of 6.2 for $15 \mathrm{~min}$ to adsorb the negatively charged $\mathrm{P}_{5} \mathrm{~W}_{30}$-GO layer, followed by washing and drying. This process was repeated until the desired number of bilayers was achieved. Such multilayer films were named $\left(\mathrm{PEI} / \mathrm{P}_{5} \mathrm{~W}_{30}-\mathrm{GO}\right)_{n}$, where $n$ is the number of bilayers (deposition cycles).

Instruments. UV-vis spectra were measured on a Beckman DU 800 spectrophotometer. IR spectra were recorded with a Nicolet 6700 FTIR spectrometer. X-ray diffraction (XRD) 

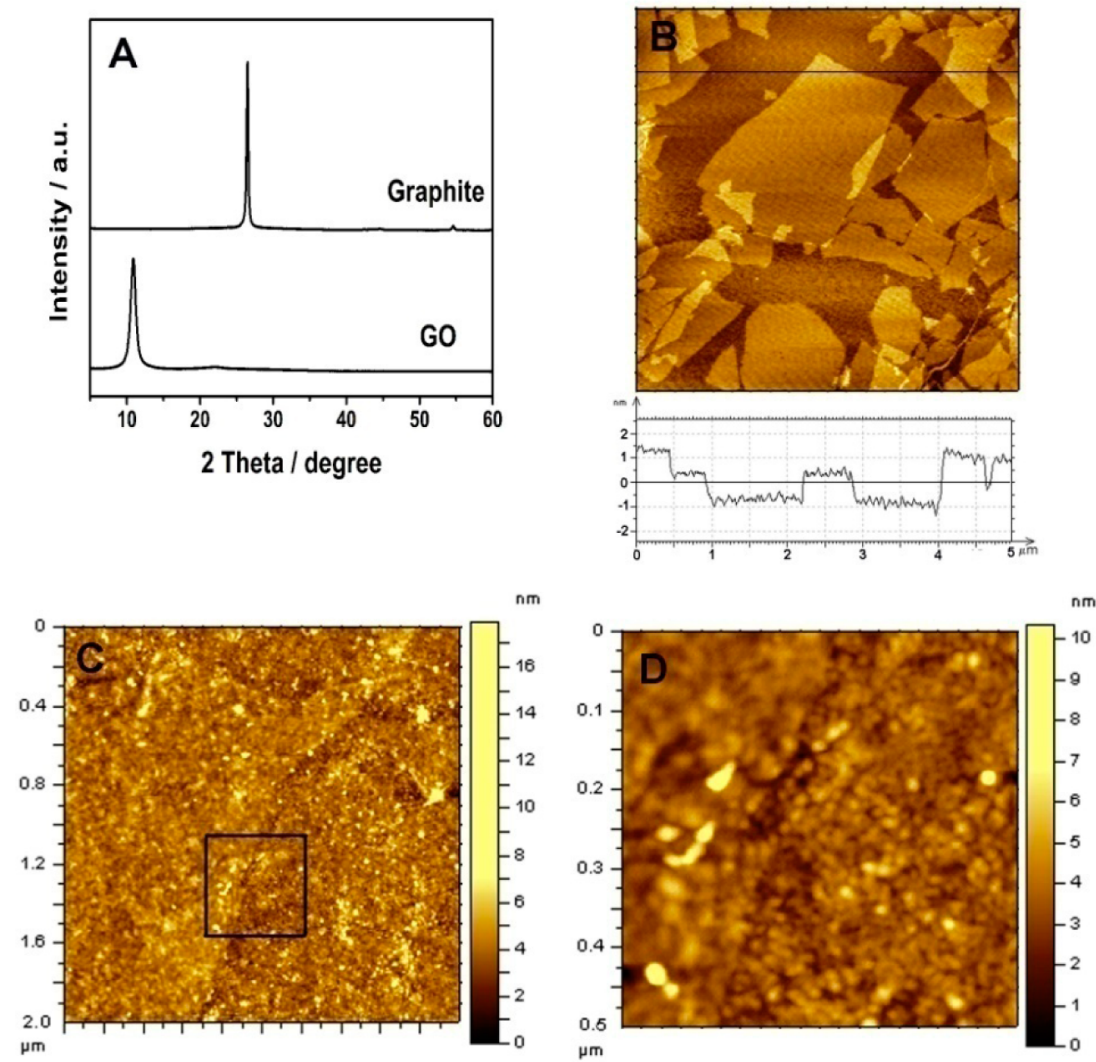

Figure 2. (A) X-ray diffraction patterns of graphite and GO. (B) AFM image of GO sheet on silicon wafer and its height profile. (C) AFM images of $\left(\mathrm{PEI} / \mathrm{P}_{5} \mathrm{~W}_{30}-\mathrm{GO}\right)_{3}$ multilayers on silicon wafer at different scales. (D) Enlargement of square domain in (C).

patterns were obtained using a Bruker D8 ADVANCE X-ray diffractometer using $\mathrm{Cu} \mathrm{K} \alpha$ radiation $\lambda=1.5418 \AA$. AFM images were recorded on an Agilent 5400 in tapping mode. XPS measurements were performed on a Thermo ESCALAB 250 spectrometer with a monochromic X-ray source (Al $\mathrm{K} \alpha$, $1486.6 \mathrm{eV}$ ) and the binding energy was corrected with the $\mathrm{C} 1 \mathrm{~s}$ $(284.6 \mathrm{eV})$ as standard. All electrochemical experiments were carried out on a model 660D Voltammetric Analyzer (CHI, Shanghai Chenhua Instrument) in a conventional onecompartment cell with a glassy carbon electrode (GCE) with a diameter of $3 \mathrm{~mm}$ as working electrode, a $\mathrm{Ag} / \mathrm{AgCl}$ ( $\mathrm{KCl}$ saturated) as reference electrode, and a Pt wire as auxiliary electrode. Rotating disk electrode (RDE) experiments were carried out on a RRDE-3A (ALS Co., Ltd.) and CHI electrochemical workstation (CHI 660D, Shanghai Chenhua Instrument). Linear sweep voltammetry (LSV) was performed at a glassy carbon $\mathrm{RDE}$ working electrode with a $3.2-\mathrm{mm}$ diameter, a platinum wire counter electrode, and a $\mathrm{Ag} / \mathrm{AgCl}$ (KCl-saturated) reference electrode. All electrochemical measurements were carried out at room temperature under nitrogen atmosphere. Photoirradiation experiments were carried out using a 500-W high-pressure mercury lamp (PLSLAM500, Shanghai Perfectlight Co., Ltd.) as the light source. The distance between the lamp and the sample was $10 \mathrm{~cm}$.

\section{RESULTS AND DISCUSSION}

Growth of Multilayers. The growth process of the multilayer films was monitored by $\mathrm{UV}$-visible absorption spectroscopy and cyclic voltammetry (CV). Figure 1A shows the UV-visible spectra of $\left(\mathrm{PEI} / \mathrm{P}_{5} \mathrm{~W}_{30}-\mathrm{GO}\right)_{n}$ multilayers with $n=1-11$ deposited on a quartz slide. The $\left(\mathrm{PEI} / \mathrm{P}_{5} \mathrm{~W}_{30}-\mathrm{GO}\right)_{n}$ multilayers could be constructed with each deposition cycle. The characteristic bands of $\mathrm{P}_{5} \mathrm{~W}_{30}$ at 215 and $270 \mathrm{~nm}$, corresponding to oxygen-to-tungsten charge-transfer (CT) transition, are showed in the inset of Figure 1A (solid line). These bands were present in the multilayer films, indicating that $\mathrm{P}_{5} \mathrm{~W}_{30}$ successfully incorporated into the films. Because of the overlap of a part of characteristic bands of $\mathrm{P}_{5} \mathrm{~W}_{30}$ and GO, as shown in the inset of Figure 1A, it was difficult to ascertain the coexistence of GO in the multilayers. Therefore, a strategy of comparing $\left(\mathrm{PEI} / \mathrm{P}_{5} \mathrm{~W}_{30}-\mathrm{GO}\right)_{n}$ and the multilayers without $\mathrm{GO}$ was developed to indirectly prove presence of $\mathrm{GO}$ in the multilayers. Another multilayer was fabricated from pure $\mathrm{P}_{5} \mathrm{~W}_{30}$ and PEI under the same conditions, and the absorbance of five $\mathrm{PEI} / \mathrm{P}_{5} \mathrm{~W}_{30}$ bilayers was approximately double than that of five $\mathrm{PEI} / \mathrm{P}_{5} \mathrm{~W}_{30}-\mathrm{GO}$ bilayers (Figure S1, Supporting Information (SI)). It clearly indicated that such a difference was caused by the presence of $\mathrm{GO}$ in $\mathrm{PEI} / \mathrm{P}_{5} \mathrm{~W}_{30}-\mathrm{GO}$ multilayers.

Figure $1 \mathrm{~B}$ shows the $\mathrm{CV}$ curves of $\left(\mathrm{PEI} / \mathrm{P}_{5} \mathrm{~W}_{30}-\mathrm{GO}\right)_{n}$ multilayers with $n=1-10$ deposited on a GCE in $5 \times 10^{-3}$ $\mathrm{mol} / \mathrm{L} \mathrm{HCl}$. Five pairs of reversible redox peaks $\left(\mathrm{I} / \mathrm{I}^{\prime}, \mathrm{II} / \mathrm{II}^{\prime}\right.$, $\mathrm{III} / \mathrm{III}^{\prime}, \mathrm{IV} / \mathrm{IV}^{\prime}$, and $\left.\mathrm{V} / \mathrm{V}^{\prime}\right)$ corresponding to the electrochemical reaction of $\mathrm{P}_{5} \mathrm{~W}_{30}$ were clearly observed in the multilayers, and their mean peak potentials $E_{1 / 2}\left[E_{1 / 2}=\left(E \mathrm{p}_{\mathrm{a}}+\right.\right.$ $\left.\left.E p_{c}\right) / 2\right]$ were $-0.215,-0.317,-0.392,-0.446$, and $-0.598 \mathrm{~V}$, respectively. The potential difference, $\Delta E\left(\Delta E=E \mathrm{p}_{\mathrm{c}}-E \mathrm{p}_{\mathrm{a}}\right)$ of each redox peak pair was near $25 \mathrm{mV}$, indicating that $\mathrm{P}_{5} \mathrm{~W}_{30}$ underwent five consecutive two-electron transfer processes. ${ }^{38}$ The current of all the redox peaks increased with the number of bilayers. Although the electrical conductivity of GO is poor, its presence in the multilayer has almost no influence on the electrochemical activity of $\mathrm{P}_{5} \mathrm{~W}_{30}$, and the $\left(\mathrm{PEI} / \mathrm{P}_{5} \mathrm{~W}_{30}-\mathrm{GO}\right)_{n}$ 



Figure 3. (A) UV-visible absorption spectra of $\left(\mathrm{PEI} / \mathrm{P}_{5} \mathrm{~W}_{30}-\mathrm{GO}\right)_{10}$ multilayers before (a) and after (b) 10 min UV-light irradiation. The insets show the photographs of $\left(\mathrm{PEI} / \mathrm{P}_{5} \mathrm{~W}_{30}-\mathrm{GO}\right)_{10}$ multilayers corresponding to curves $a$ and $b$. (B) XPS spectra of $\left(\mathrm{PEI} / \mathrm{P}_{5} \mathrm{~W}_{30}-\mathrm{GO}\right)_{5}$ multilayers before $(\mathrm{c})$ and after (d) the UV-light irradiation.

multilayers still exhibited uniform growth without any shift in the peak potential.

Morphology of $\left(\mathrm{PEI} / \mathrm{P}_{5} \mathrm{~W}_{30}-\mathrm{GO}\right)_{n}$ Multilayers. Figure $2 \mathrm{~A}$ shows the XRD patterns of graphite flakes and GO. The sharp peak centered at $2 \theta=26.4^{\circ}$ corresponds to the (002) interplanar spacing of $0.34 \mathrm{~nm}$ in graphite flakes. After a series of oxidations, a well-defined peak at a lower diffraction angle of $2 \theta=10.8^{\circ}$ indicatd a regular interlayer distance of $0.82 \mathrm{~nm}$ in GO. The presence of oxygen-bearing groups such as epoxides, hydroxyls, and carboxyls increased the basal spacing of GO after the oxidation. Figure 2B shows the AFM image of GO sheets on silicon wafer, where the sheet structures are clearly visible. From the height profiles, the GO sheet measures $\sim 1.2 \mathrm{~nm}$ in thickness. The value of the order of $0.9-1.3 \mathrm{~nm}$ is regarded as the typical thickness of single-sheet GO.

The surface morphology of $\left(\mathrm{PEI} / \mathrm{P}_{5} \mathrm{~W}_{30}-\mathrm{GO}\right)_{3}$ multilayers on silicon wafer was characterized by AFM. Clearly, the compact structure covered the silicon substrate as shown in Figure 2C, where some lamellar films were dimly visible with the appearance of aggregated nanoparticles underneath. After the enlargement of the square domain of Figure 2C, Figure 2D clearly shows a boundary between a transparent monolayer of GO sheet and the underneath nanoparticles. Such a granular texture indicated that a typical morphology of the multilayers was composed of POMs and polyelectrolytes. This demonstrated that two types of negatively charged species, $\mathrm{P}_{5} \mathrm{~W}_{30}$ and $\mathrm{GO}$, distributed in the multilayers.

Spectral Characterization of $\left(\mathrm{PEI} / \mathrm{P}_{5} \mathrm{~W}_{30}-\mathrm{GO}\right)_{\mathrm{n}}$ Multilayers with/without UV-Light Irradiation. During the UVlight irradiation, the color of $\left(\mathrm{PEI} / \mathrm{P}_{5} \mathrm{~W}_{30}-\mathrm{GO}\right)_{10}$ multilayer clearly changed. As shown in the inset of Figure 3A, the palebrown (PEI/ $\left.\mathrm{P}_{5} \mathrm{~W}_{30}-\mathrm{GO}\right)_{10}$ multilayers (photo a, Figure $3 \mathrm{~A}$ ) on quartz slide changed to the black multilayer (photo $b$, Figure 3A) after $10 \mathrm{~min}$ UV-light irradiation. The comparison of the corresponding UV-visible absorption spectra of the asprepared multilayers (curve $a$, Figure $3 \mathrm{~A}$ ) and irradiated multilayers (curve $b$, Figure $3 \mathrm{~A}$ ), showed the increase in the absorbance of multilayers from 250 to $700 \mathrm{~nm}$. This was typical for a transfer of electrons to GO accompanied by a partial restoration of the conjugated aromatic structure. ${ }^{20}$ Prolonged UV irradiation did not cause further increase of the absorbance, indicating that the photoreduction of GO in the multilayer was rapid and reached the saturation point. XPS was a powerful technology to detect the compositional changes of carbon atoms in GO with different chemical states before and after the UV-light irradiation. By comparing the amounts of epoxide and hydroxyl groups, the extent of photoreduced GO could be confirmed. The XPS spectra of the as-prepared $\left(\mathrm{PEI} / \mathrm{P}_{5} \mathrm{~W}_{30}-\right.$ $\mathrm{GO})_{5}$ multilayers were resolved into four peaks corresponding to four types of $\mathrm{C} 1 \mathrm{~s}$ (curve $c$, Figure 3B), containing $4.0 \%$ of $\mathrm{O}-\mathrm{C}=\mathrm{O}$ centered $\sim 289.3 \mathrm{eV}, 9.0 \%$ of $\mathrm{C}=\mathrm{O}$ centered $\sim 288.2$ $\mathrm{eV}, 43.7 \%$ of $\mathrm{C}-\mathrm{O}$ centered $\sim 286.4 \mathrm{eV}$, and $43.3 \%$ of $\mathrm{sp}^{2} \mathrm{C}-\mathrm{C}$ centered $\sim 284.6 \mathrm{eV}$. After the UV-light irradiation, the content of $\mathrm{sp}^{2} \mathrm{C}-\mathrm{C}$ increased to $65.8 \%$, while a total of only $34.2 \%$ oxygenated carbon remained in the irradiated multilayers (curve $d$, Figure $3 \mathrm{~B}$ ). In other words, the content of $\mathrm{sp}^{2} \mathrm{C}-$ $\mathrm{C}$ increased by near $22 \%$. This indicated that GO was partially reduced by the deoxygenation of GO under UV-light irradiation. The irradiated multilayers were named as (PEI/ $\left.\mathrm{P}_{5} \mathrm{~W}_{30}-\mathrm{RGO}\right)_{n}$

Although the photoreduction of GO has been confirmed, the photoreaction mechanism should be clearly elucidated. Unlike other photocatalysts, such as $\mathrm{TiO}_{2}$, most POTs themselves cannot be photoexcited to produce electron-hole separation. However, using protonated alkylammonium, photogenerated electrons and holes in POTs, which were produced by $\mathrm{O} \rightarrow \mathrm{W}$ ligand-to-metal charge transfer (LMCT), could be effectively achieved. ${ }^{39}$ For example in $\left(\mathrm{PEI} / \mathrm{P}_{5} \mathrm{~W}_{30}\right)_{10}$ multilayers, the UVlight irradiation afforded a colored charge-transfer complex between PEI and $\mathrm{P}_{5} \mathrm{~W}_{30} \cdot{ }^{34}$ It is well-known that a proton from $\mathrm{H}$-bonded $\mathrm{N}$ of PEI was transferred to a bridging oxygen atom in the edge-shared $\mathrm{WO}_{6}$ octahedral lattice, and then the hopping $\mathrm{d}^{1}$ electron from $\mathrm{WO}_{6}$ octahedron could interact with this proton. At the same time, the hole left at the oxygen atom resulting from $\mathrm{O} \rightarrow \mathrm{W}$ LMCT interacted with the nonbonding electrons on the $\mathrm{N}$ atom of PEI. Such a consecutive process accomplished the effective separation of electrons and holes and stabilized the colored state of the complex. When GO was present in the multilayers, the nonbonding electrons of $\mathrm{N}$ atoms trapped in the $\mathrm{WO}_{6}$ octahedron cluster could be further transferred to $\mathrm{GO}$, thus reducing the $\mathrm{GO}$, and recombing the electrons and holes in $\mathrm{P}_{5} \mathrm{~W}_{30}$. A plausible photoreduction mechanism for GO in multilayers is shown in Scheme 1. As expected, $\mathrm{P}_{5} \mathrm{~W}_{30}$ acted as a photocatalyst and electron-transfer

Scheme 1. Photoreduction Process of GO in $\left(\mathrm{PEI} / \mathrm{P}_{5} \mathrm{~W}_{30}-\right.$ GO) ${ }_{n}$ Multilayers

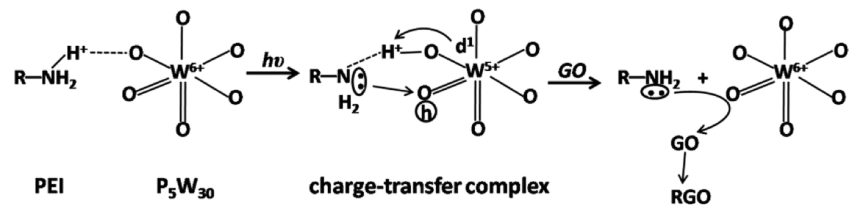



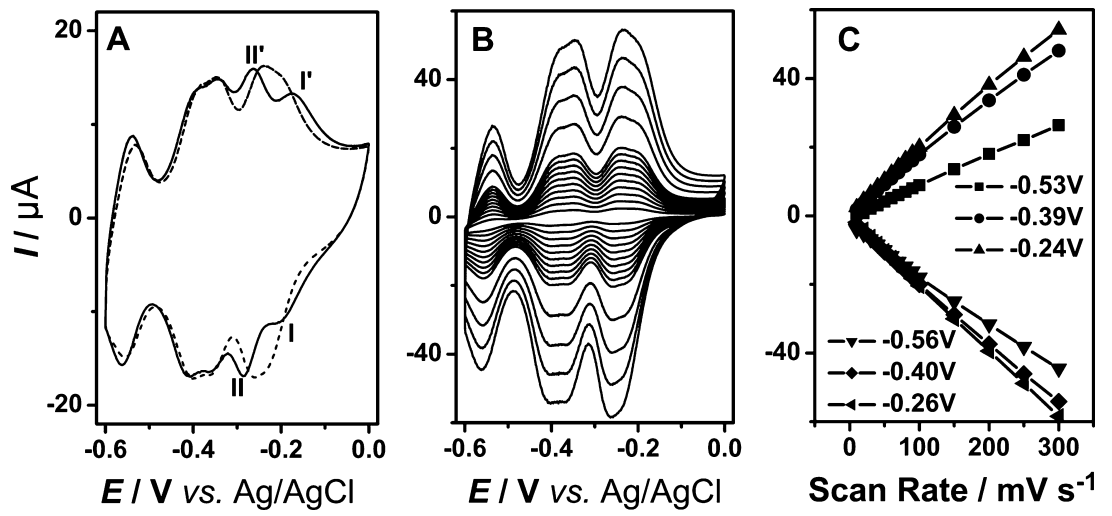

Figure 4. (A) Cyclic voltammograms of $\left(\mathrm{PEI} / \mathrm{P}_{5} \mathrm{~W}_{30}-\mathrm{GO}\right)_{10}$ multilayers before (solid curve) and after UV-light irradiation (dash curve) modified on GCE in $5 \times 10^{-3} \mathrm{~mol} / \mathrm{L} \mathrm{HCl}$ solution at a scan rate of $50 \mathrm{mV} / \mathrm{s}$. (B) Cyclic voltammograms of $\left(\mathrm{PEI} / \mathrm{P}_{5} \mathrm{~W}_{30}-\mathrm{RGO}\right)_{10}$ multilayers modified on GCE in $5 \times 10^{-3} \mathrm{~mol} / \mathrm{L} \mathrm{HCl}$ solution at different scan rates (from inner to outer: 10, 20, 30, 40,50,60, 70, 80, 90, 100, 150, 200, 250, and 300 mV/s). (C) Variation in the cathodic (negative current) and anodic (positive current) peak currents with increasing scan rate.

mediator to accomplish the reduction of GO driven by UV light. Moreover, the close contact between $\mathrm{P}_{5} \mathrm{~W}_{30}$ and $\mathrm{GO}$ in the same layer leads to a more efficient photoreduction process compared to that in individual POTs and GO layers separated by a polyelectrolyte layer. ${ }^{21}$

In the XPS spectra of $\left(\mathrm{PEI} / \mathrm{P}_{5} \mathrm{~W}_{30}-\mathrm{RGO}\right)_{5}$ multilayers (Figure S2, SI), the peaks corresponding to $\mathrm{W} 4 \mathrm{f}_{7 / 2}$ and $\mathrm{W} 4 \mathrm{f}_{5 / 2}$ slightly shifted from 35.7 and $37.8 \mathrm{eV}$ to 35.5 and $37.5 \mathrm{eV}$, respectively. This indicates that UV-light irradiation induced the reduction of $\mathrm{W}^{6+}$ to the colored species, $\mathrm{W}^{5+}$, and parts of the colored charge-transfer complex still remained despite the transfer of electrons to $\mathrm{GO}$ for its reduction. On the other hand, the presence of GO also enhanced the stability of the charge-transfer complex. As for the changes in PEI in photoreduction reaction, the $\mathrm{N} 1 \mathrm{~s}$ spectrum was used to determine the $\mathrm{N}$ configurations in PEI using XPS spectra. As shown in SI Figure S3a, the $\mathrm{N}$ 1s spectrum of $\left(\mathrm{PEI} / \mathrm{P}_{5} \mathrm{~W}_{30}-\right.$ $\mathrm{GO})_{5}$ multilayers was deconvoluted to several individual peaks which were assigned to protonated $\mathrm{N}(401.9 \mathrm{eV}), \mathrm{NH}_{2}(400.4$ $\mathrm{eV})$, and $\mathrm{NH}(399.5 \mathrm{eV}) .{ }^{40}$ After the UV-light irradiation, the $\mathrm{N}$ 1s spectra shown in SI Figure S3b were slightly narrowed, and the relative contents of protonated $\mathrm{N}$ decreased. This was caused by two factors: (1) the synergistic effect of $\mathrm{W}$ and the donated electrons of $-\mathrm{NH}_{2}{ }^{40}$ and (2) the photodecomposition of the PEI moiety. In fact, the presence of a transferable proton in a $\mathrm{H}$ bond between PEI and $\mathrm{P}_{5} \mathrm{~W}_{30}$ was essential to obtain electron-hole separation species for the further reduction of GO. The photoreduction of GO cannot take place without PEI.

Electrochemical Behavior of (PEI/P $\left.\mathrm{P}_{5} \mathrm{~W}_{30}-\mathrm{RGO}\right)_{n}$ Multilayers. After the UV-light irradiation, the redox peaks of (PEI/ $\left.\mathrm{P}_{5} \mathrm{~W}_{30}-\mathrm{GO}\right)_{10}$ multilayers displayed some changes as shown in Figure 4A. The first two pairs of redox peaks, I/I' and II/II', approached each other to form overlapped peaks (dashed curve), while the other peaks remained unchanged. The main reason was the valence changes in $\mathrm{W}$ atom from +6 to +5 upon UV-light irradiation. The CVs of $\left(\mathrm{PEI} / \mathrm{P}_{5} \mathrm{~W}_{30}-\mathrm{RGO}\right)_{10}$ multilayers modified on $\mathrm{GCE}$ at different scan rates are shown in Figure 4B. Clearly, the potential of five redox peaks did not change with increasing scan rate. However, the hysteresis phenomenon of reductive and oxidative current waves with increasing scan rates occurred in the as-prepared $\left(\mathrm{PEI} / \mathrm{P}_{5} \mathrm{~W}_{30}-\right.$ $\mathrm{GO})_{10}$ multilayers as shown in SI Figure S4. In general, the electron transfer reaction is regarded as slow in an electrochemical process when the potential difference $\Delta E$ increases with scan rate. As for the irradiated multilayers, the formation of graphene in the multilayers probably accelerated the electron transfer reaction. Therefore, no hysteresis of five redox potentials occurred with increasing scan rate in $\left(\mathrm{PEI} / \mathrm{P}_{5} \mathrm{~W}_{30}-\right.$ RGO) ${ }_{10}$ multilayers. A good linearity in the plot of peak current vs scan rate up to $300 \mathrm{mV} / \mathrm{s}$ indicates that the electrochemical behavior of $\left(\mathrm{PEI} / \mathrm{P}_{5} \mathrm{~W}_{30}-\mathrm{RGO}\right)_{10}$ multilayers showed a fast, surface-controlled electron transfer process, as shown in Figure $4 \mathrm{C}$. Furthermore, $\left(\mathrm{PEI} / \mathrm{P}_{5} \mathrm{~W}_{30}-\mathrm{RGO}\right)_{10}$ multilayers were very stable during the electrochemical scan.

Electrocatalytic Behavior of Multilayers toward ORR. The electrocatalytic activity of $\left(\mathrm{PEI} / \mathrm{P}_{5} \mathrm{~W}_{30}-\mathrm{RGO}\right)_{n}$ multilayers toward ORR was evaluated in $5 \times 10^{-2} \mathrm{~mol} / \mathrm{L} \mathrm{H}_{2} \mathrm{SO}_{4}$ solution. Figure 5 shows the voltammograms of $\left(\mathrm{PEI} / \mathrm{P}_{5} \mathrm{~W}_{30}-\mathrm{RGO}\right)_{10}$

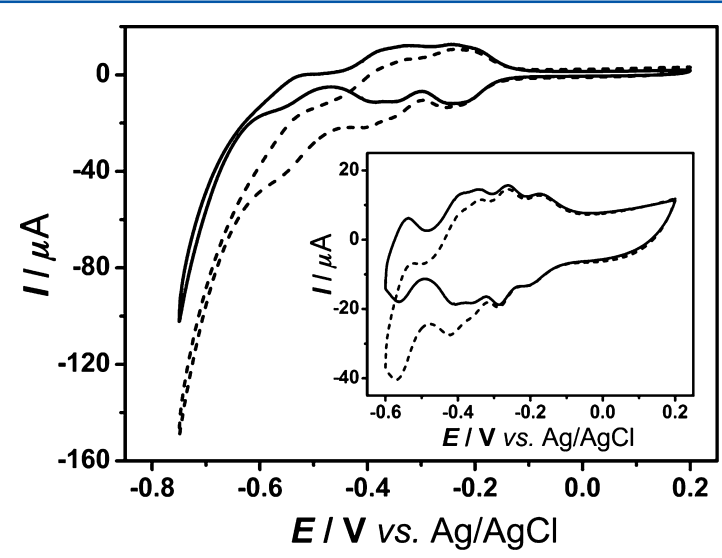

Figure 5. Cyclic voltammograms of $\left(\mathrm{PEI} / \mathrm{P}_{5} \mathrm{~W}_{30}-\mathrm{RGO}\right)_{10}$ multilayers modified on GCE in $\mathrm{N}_{2}$-saturated (solid line) and $\mathrm{O}_{2}$-saturated (dashed line) $5 \times 10^{-2} \mathrm{~mol} / \mathrm{L} \mathrm{H}_{2} \mathrm{SO}_{4}$ solution. Insets show the $\mathrm{CVs}$ of $\left(\mathrm{PEI} / \mathrm{P}_{5} \mathrm{~W}_{30}\right)_{10}$ multilayers modified on GCE in $\mathrm{N}_{2}$-saturated (solid line) and $\mathrm{O}_{2}$-saturated (dashed line) $5 \times 10^{-2} \mathrm{~mol} / \mathrm{L} \mathrm{H}_{2} \mathrm{SO}_{4}$ solution. Scan rate: $50 \mathrm{mV} / \mathrm{s}$.

multilayers modified on GCE in $\mathrm{N}_{2}$ - and $\mathrm{O}_{2}$-saturated solutions in the potential range from 0.2 to $-0.75 \mathrm{~V}$. When the electrolyte solution was saturated with $\mathrm{O}_{2}$, the cathodic peak current increased from an onset potential of $-0.2 \mathrm{~V}$, while the reversed anodic peak current decreased (as shown in the dashline curve) compared to the solid-line curve. This onset potential for ORR was ca. $-0.2 \mathrm{~V}$, where the first 2e-reduction of $\mathrm{P}_{5} \mathrm{~W}_{30}$ occurred. This indicates that the ORR was 
electrocatalyzed by $\mathrm{P}_{5} \mathrm{~W}_{30}$. To find the effect of $\mathrm{RGO}$ on electrocatalytic ORR, the electrocatalytic behavior of (PEI/ $\left.\mathrm{P}_{5} \mathrm{~W}_{30}\right)_{10}$ multilayers without RGO was investigated. As shown in the inset of Figure 5, the $\left(\mathrm{PEI} / \mathrm{P}_{5} \mathrm{~W}_{30}\right)_{10}$ multilayers also exhibited an electrocatalytic activity toward ORR with an onset potential of $-0.28 \mathrm{~V}$. The result proved that the $\mathrm{P}_{5} \mathrm{~W}_{30}$ in multilayers played a major role in electrocatalyzing ORR, and RGO promoted the advance of onset potential for ORR $\sim 80$ $\mathrm{mV}$.

A more detailed analysis of the electrocatalytic behavior of $\left(\mathrm{PEI} / \mathrm{P}_{5} \mathrm{~W}_{30}-\mathrm{RGO}\right)_{10}$ multilayers toward ORR was carried out by $\mathrm{RDE}$ measurements. Figure 6 shows the typical RDE curves



Figure 6. Linear sweep voltammograms of $\left(\mathrm{PEI} / \mathrm{P}_{5} \mathrm{~W}_{30}-\mathrm{RGO}\right)_{10}$ multilayers modified on $\mathrm{RDE}$ in $\mathrm{O}_{2}$-saturated $5 \times 10^{-2} \mathrm{~mol} / \mathrm{L}$ $\mathrm{H}_{2} \mathrm{SO}_{4}$ solution with various rotation rates at a scan rate of $2 \mathrm{mV} / \mathrm{s}$. The rotation rates are 400, 800, 1000, 1200, 1600, and $2000 \mathrm{rpm}$. The insets are the Koutecky-Levich plots of $\left(\mathrm{PEI} / \mathrm{P}_{5} \mathrm{~W}_{30}-\mathrm{RGO}\right)_{10}$ multilayers at different electrode potentials.

obtained at different rotation rates, where the current density was enhanced by increasing the rotation rate from 400 to 2000 rpm. The Koutecky-Levich plots, ${ }^{41}$ as shown in the inset of Figure 6, were obtained as a linear fit of the data obtained from the corresponding polarization curves (Figure 6) by applying the reported values for oxygen solubility diffusivity $(D=1.4 \times$ $10^{-5} \mathrm{~cm}^{2} / \mathrm{s}$ ) and the kinematic viscosity of $5 \times 10^{-2} \mathrm{~mol} / \mathrm{L}$ $\mathrm{H}_{2} \mathrm{SO}_{4}$ electrolyte $\left(\nu=0.01 \mathrm{~cm}^{2} / \mathrm{s}\right)$ to $0.62 \mathrm{nFAD}^{2 / 3} \nu^{-1 / 6} \mathrm{C}_{\mathrm{O} 2}$ equation. ${ }^{42}$ From the slope of Koutecky-Levich plots at -0.4 , -0.5 , and $-0.6 \mathrm{~V}$, the $B$ factors were estimated to be $3.5,5.4$, and $7.4 \mu \mathrm{A} \cdot \mathrm{rpm}^{-1 / 2}$, respectively. According to the value of $B$, the number of electrons transferred during the reduction of an oxygen molecule was calculated to be about 1.9 electrons at $-0.4 \mathrm{~V}, 2.9$ electrons at $-0.5 \mathrm{~V}$, and 4 electrons at $-0.6 \mathrm{~V}$. At a potential of $-0.4 \mathrm{~V}$, ORR occurred via the almost two-electron reduction pathway where it was reduced to $\mathrm{H}_{2} \mathrm{O}_{2}$. At a potential of $-0.6 \mathrm{~V}$, ORR occurred via almost a four-electron reduction pathway where oxygen was reduced to $\mathrm{H}_{2} \mathrm{O}$.

Electrocatalytic Behavior of Multilayers toward HER. The electrocatalytic activity of multilayers immobilized on GCE toward HER was investigated. As shown in Figure 7a, HER did not occur on the bare GCE before the potential of $-0.8 \mathrm{~V}$ in 5 $\times 10^{-2} \mathrm{~mol} / \mathrm{L} \mathrm{H}_{2} \mathrm{SO}_{4}$ aqueous solution. When $\left(\mathrm{PEI} / \mathrm{P}_{5} \mathrm{~W}_{30}-\right.$ $\mathrm{GO})_{10}$ multilayers were immobilized on GCE, the reduction of $\mathrm{H}^{+}$in $5 \times 10^{-2} \mathrm{~mol} / \mathrm{L} \mathrm{H}_{2} \mathrm{SO}_{4}$ aqueous solution still did not occur, as shown in Figure $7 \mathrm{~b}$, in the same potential range. After the UV-light irradiation, the $\left(\mathrm{PEI} / \mathrm{P}_{5} \mathrm{~W}_{30}-\mathrm{RGO}\right)_{10}$ multilayers exhibited good electrocatalytic activity for HER with a rapid increase in the cathodic peak current from the potential of -0.6

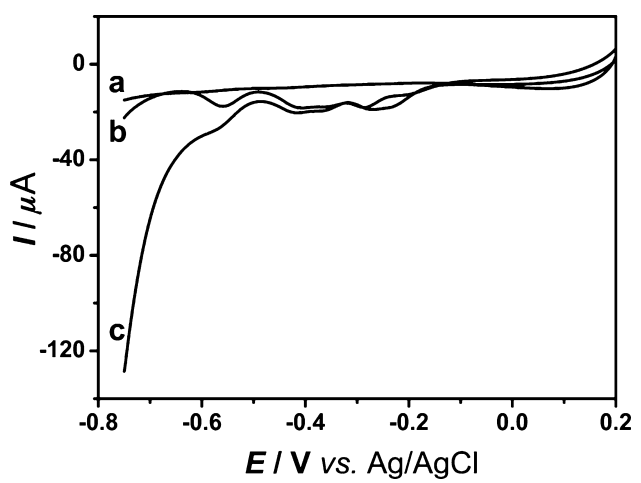

Figure 7. LSV of bare GCE (a), $\left(\mathrm{PEI} / \mathrm{P}_{5} \mathrm{~W}_{30}-\mathrm{GO}\right)_{10}$ multilayers (b), and $\left(\mathrm{PEI} / \mathrm{P}_{5} \mathrm{~W}_{30}-\mathrm{RGO}\right)_{10}$ multilayers (c) immobilized on GCE in a 5 $\times 10^{-2} \mathrm{~mol} / \mathrm{L} \mathrm{H}_{2} \mathrm{SO}_{4}$ at a scan rate of $50 \mathrm{mV} / \mathrm{s}$.

$\mathrm{V}$, as shown in Figure 7c. This result indicates that the RGO in multilayer played a crucial role in electrocatalyzing HER.

\section{CONCLUSIONS}

POTs/G nanocomposite multilayers based on Pressler-type POT and reduced graphene oxide (RGO) were successfully constructed by LbL self-assembly route combined with postphotoreduction method. In this method, $\mathrm{P}_{5} \mathrm{~W}_{30}$ clusters and GO were codeposited on different substrates to afford $\left(\mathrm{PEI} / \mathrm{P}_{5} \mathrm{~W}_{30}-\mathrm{GO}\right)_{n}$ multilayers by alternate electrostatic adsorption with protonated PEI, and the subsequent UV-light irradiation afforded $\mathrm{RGO}$ in the multilayers. $\left(\mathrm{PEI} / \mathrm{P}_{5} \mathrm{~W}_{30}-\right.$ $\mathrm{GO})_{n}$ multilayer films could grow consecutively, and GO was distributed in each bilayer of multilayers. The formation of charge-transfer complex between $\mathrm{P}_{5} \mathrm{~W}_{30}$ and PEI produced by UV-light irradiation accomplished the transfer of electrons from PEI to GO for the RGO synthesis. In this photoreduction process, $\mathrm{P}_{5} \mathrm{~W}_{30}$ acted as the photocatalyst and electron-transfer mediator to realize the reduction of GO driven by UV-light. Two components of $\mathrm{P}_{5} \mathrm{~W}_{30}$ and RGO afforded the (PEI/ $\left.\mathrm{P}_{5} \mathrm{~W}_{30}-\mathrm{RGO}\right)_{n}$ multilayer bifunctionality in electrocatalytic field. The multilayers present good electrocatalytic activity toward ORR because of the role of $\mathrm{P}_{5} \mathrm{~W}_{30}$. Furthermore, the multilayers clearly exhibited HER signal because of the presence of RGO in multilayers. Such a synthetic strategy could extend the application of POTs/G composites to the electrocatalysis of ORR and HER.

\section{ASSOCIATED CONTENT}

\section{S Supporting Information}

UV-vis spectra, XPS spectra, and cyclic voltammograms of multilayers. This material is available free of charge via the Internet at http://pubs.acs.org.

\section{AUTHOR INFORMATION}

\section{Corresponding Authors}

*E-mail:hongyuzhang@ouc.edu.cn.

*E-mail:zhaoxb@qibebt.ac.cn.

\section{Notes}

The authors declare no competing financial interest.

\section{ACKNOWLEDGMENTS}

This work was financially supported by National Natural Science Foundation of China (Grants 21103215, 21173246, 20804042). 


\section{REFERENCES}

(1) Geim, A. K.; Novoselov, K. S. The Rise of Graphene. Nat. Mater. 2007, 6, 183-191.

(2) Xie, G. C.; Zhang, K.; Guo, B. D.; Liu, Q.; Fang, L.; Gong, J. R. Graphene-Based Materials for Hydrogen Generation from LightDriven Water Splitting. Adv. Mater. 2013, 25, 3820-3839.

(3) Kim, Y. K.; Han, S. W.; Min, D. H. Graphene Oxide Sheath on Ag Nanoparticle/Graphene Hybrid Films as an Antioxidative Coating and Enhancer of Surface-Enhanced Raman Scattering. ACS Appl. Mater. Interfaces 2012, 4, 6545-6551.

(4) Seger, B.; Kamat, P. V. Electrocatalytically Active GraphenePlatinum Nanocomposites. Role of 2-D Carbon Support in Pem Fuel Cells. J. Phys. Chem. C 2009, 113, 7990-7995.

(5) Zhang, K.; Zhang, L. L.; Zhao, X. S.; Wu, J. Graphene/Polyaniline Nanofiber Composites as Supercapacitor Electrodes. Chem. Mater. 2010, 22, 1392-1401.

(6) Williams, G.; Seger, B.; Kamat, P. V. TiO 2 -Graphene Nanocomposites. UV-Assisted Photocatalytic Reduction of Graphene Oxide. ACS Nano 2008, 2, 1487-1491.

(7) Wang, Q. H.; Jiao, L. F.; Du, H. M.; Wang, Y. J.; Yuan, H. T. $\mathrm{Fe}_{3} \mathrm{O}_{4}$ Nanoparticles Grown on Graphene as Advanced Electrode Materials for Supercapacitors. J. Power Sources 2014, 245, 101-106.

(8) Zeng, G.; Xing, Y.; Gao, J.; Wang, Z.; Zhang, X. Unconventional Layer-by-Layer Assembly of Graphene Multilayer Films for EnzymeBased Glucose and Maltose Biosensing. Langmuir 2010, 26, 1502215026.

(9) Liu, R.; Li, S.; Yu, X.; Zhang, G.; Zhang, S.; Yao, J.; Keita, B.; Nadjo, L.; Zhi, L. Facile Synthesis of Au-Nanoparticle/Polyoxometalate/Graphene Tricomponent Nanohybrids: An Enzyme-Free Electrochemical Biosensor for Hydrogen Peroxide. Small 2012, 8, 13981406.

(10) Zhang, Q. L.; Xu, T. Q.; Wei, J.; Chen, J. R.; Wang, A. J.; Feng, J. J. Facile Synthesis of Uniform Pt Nanoparticles on PolydopamineReduced Graphene Oxide and Their Electrochemical Sensing. Electrochim. Acta 2013, 112, 127-132.

(11) Xu, C. H.; Xu, B. H.; Gu, Y.; Xiong, Z. G.; Sun, J.; Zhao, X. S. Graphene-Based Electrodes for Electrochemical Energy Storage. Energy Environ. Sci. 2013, 6, 1388-1414.

(12) Long, D.-L.; Burkholder, E.; Cronin, L. Polyoxometalate Clusters, Nanostructures and Materials: From Self Assembly to Designer Materials and Devices. Chem. Soc. Rev. 2007, 36, 105.

(13) Stracke, J. J.; Finke, R. G. Electrocatalytic Water Oxidation Beginning with the Cobalt Polyoxometalate $\mathrm{Co}_{4}\left(\mathrm{H}_{2} \mathrm{O}\right)_{2}\left(\mathrm{PW}_{9} \mathrm{O}_{34}\right)_{2}{ }^{10-}$ : Identification of Heterogeneous $\mathrm{CoOx}$ as the Dominant Catalyst. J. Am. Chem. Soc. 2011, 133, 14872-14875.

(14) Cronin, L.; Molina, P. I.; Miras, H. N. Polyoxometalate-Based Solar Cells for Water Splitting. Solar Hydrogen and Nanotechnology VI. Proc. SPIE 2011, 8109, No. 10.1117/12.895296.

(15) Toma, F. M.; Sartorel, A.; Iurlo, M.; Carraro, M.; Parisse, P.; Maccato, C.; Rapino, S.; Gonzalez, B. R.; Amenitsch, H.; Da Ros, T.; et al. Efficient Water Oxidation at Carbon Nanotube-Polyoxometalate Electrocatalytic Interfaces. Nat. Chem. 2010, 2, 826-831.

(16) Coquelard, C. C.; Sébastien Sorgues, S.; Ruhlmann, L. Photocatalysis with Polyoxometalates Associated to Porphyrins under Visible Light: An Application of Charge Transfer in Electrostatic Complexes. J. Phys. Chem. A 2010, 114, 6394-6400.

(17) Kovtyukhova, N. I.; Ollivier, P. J.; Martin, B. R.; Mallouk, T. E.; Chizhik, S. A.; Buzaneva, E. V.; Gorchinskiy, A. D. Layer-by-Layer Assembly of Ultrathin Composite Films from Micron-Sized Graphite Oxide Sheets and Polycations. Chem. Mater. 1999, 11, 771-778.

(18) Petit, C.; Bandosz, T. J. Graphite Oxide/Polyoxometalate Nanocomposites as Adsorbents of Ammonia. J. Phys. Chem. C 2009, $113,3800-3809$.

(19) Zhou, D.; Han, B.-H. Graphene-Based Nanoporous Materials Assembled by Mediation of Polyoxometalate Nanoparticles. Adv. Funct. Mater. 2010, 20, 2717-2722.

(20) Li, H. L.; Pang, S. P.; Feng, X. L.; Muellen, K.; Bubeck, C. Polyoxometalate Assisted Photoreduction of Graphene Oxide and Its Nanocomposite Formation. Chem. Commun. 2010, 6243-6245 2010.
(21) Li, H. L.; Pang, S. P.; Wu, S.; Feng, X. L.; Müllen, K.; Bubeck, C. Layer-by-Layer Assembly and UV Photoreduction of GraphenePolyoxometalate Composite Films for Electronics. J. Am. Chem. Soc. 2011, 133, 9423-9429.

(22) Marleny Rodriguez-Albelo, L.; Rousseau, G.; Mialane, P.; Marrot, J.; Mellot-Draznieks, C.; Rabdel Ruiz-Salvador, A.; Li, S.; Liu, R.; Zhang, G.; Keita, B.; et al. Epsilon-Keggin-Based Coordination Networks: Synthesis, Structure and Application toward Green Synthesis of Polyoxometalate@Graphene Hybrids. Dalton Trans. 2012, 41, 9989-9999.

(23) Wang, J. J.; Han, D. X.; Wang, X. H.; Qi, B.; Zhao, M. S. Polyoxometalates as Peroxidase Mimetics and Their Applications in $\mathrm{H}_{2} \mathrm{O}_{2}$ and Glucose Detection. Biosens. Bioelectron. 2012, 36, 18-21.

(24) Zhang, H.; Xie, A.; Shen, Y.; Qiu, L.; Tian, X. Layer-by-Layer Inkjet Printing of Fabricating Reduced Graphene-Polyoxometalate Composite Film for Chemical Sensors. Phys. Chem. Chem. Phys. 2012, 14, 12757-12763.

(25) Guo, S. X.; Liu, Y. P.; Lee, C.-Y.; Bond, A. M.; Zhang, J.; Geletii, Y. V.; Hill, C. L. Graphene-Supported $\left\{\mathrm{Ru}_{4} \mathrm{O}_{4}(\mathrm{OH})_{2}\left(\mathrm{H}_{2} \mathrm{O}\right)_{4}\right\}$ (Gamma-SiW $\left.{ }_{10} \mathrm{O}_{36}\right)_{2}{ }^{10-}$ for Highly Efficient Electrocatalytic Water Oxidation. Energy Environ. Sci. 2013, 6, 2654-2663.

(26) Kim, Y.; Shanmugam, S. Polyoxometalate-Reduced Graphene Oxide Hybrid Catalyst: Synthesis, Structure, and Electrochemical Properties. ACS Appl. Mater. Interfaces 2013, 5, 12197-12204.

(27) Li, S. W.; Liu, R. J.; Ngo Biboum, R.; Lepoittevin, B.; Zhang, G.; Dolbecq, A.; Mialane, P.; Keita, B. First Examples of Hybrids Based on Graphene and a Ring-Shaped Macrocyclic Polyoxometalate: Synthesis, Characterization, and Properties. Eur. J. Inorg. Chem. 2013, 2013, $1882-1889$.

(28) Tessonnier, J.-P.; Goubert-Renaudin, S.; Alia, S.; Yan, Y.; Barteau, M. A. Structure, Stability, and Electronic Interactions of Polyoxometalates on Functionalized Graphene Sheets. Langmuir 2013, 29, 393-402.

(29) Wang, S.; Li, H. L.; Li, S.; Liu, F.; Wu, D. Q.; Feng, X. L.; Wu, L. $\mathrm{X}$. Electrochemical-Reduction-Assisted Assembly of a Polyoxometalate/Graphene Nanocomposite and Its Enhanced Lithium-Storage Performance. Chem.-Eur. J. 2013, 19, 10895-10902.

(30) Decher, G. Fuzzy Nanoassemblies: Toward Layered Polymeric Multicomposites. Science 1997, 277, 1232-1237.

(31) Liu, R. J.; Li, S. W.; Yu, X. L.; Zhang, G. J.; Zhang, S. J.; Yao, J. N.; Zhi, L. J. A General Green Strategy for Fabricating Metal Nanoparticles/Polyoxometalate/Graphene Tri-Component Nanohybrids: Enhanced Electrocatalytic Properties. J. Mater. Chem. 2012, 22, 3319-3322.

(32) Lu, Y. C.; Gasteiger, H. A.; Shao-Horn, Y. Catalytic Activity Trends of Oxygen Reduction Reaction for Nonaqueous Li-Air Batteries. J. Am. Chem. Soc. 2011, 133, 19048-19051.

(33) Nohra, B.; El Moll, H.; Albelo, L. M. R.; Mialane, P.; Marrot, J.; Mellot-Draznieks, C.; O’Keeffe, M.; Biboum, R. N.; Lemaire, J.; Keita, B.; et al. Polyoxometalate-Based Metal Organic Frameworks (Pomofs): Structural Trends, Energetics, and High Electrocatalytic Efficiency for Hydrogen Evolution Reaction. J. Am. Chem. Soc. 2011, 133, 13363-13374.

(34) Jiang, M.; Wang, E. B.; Wei, G.; Xu, L.; Kang, Z. H.; Li, Z. A Novel Photochromic Multilayer Based on Preyssler's Cluster. New J. Chem. 2003, 27, 1291-1293.

(35) Alizadeh, M. H.; Harmalker, S. P.; Jeannin, Y.; Martinfrere, J.; Pope, M. T. A Heteropolyanion with Fivefold Molecular Symmetry That Contains a Nonlabile Encapsulated Sodium-Ion - The Structure and Chemistry of $\left[\mathrm{NaP}_{5} \mathrm{~W}_{30} \mathrm{O}_{110}\right]^{14-}$. J. Am. Chem. Soc. 1985, 107, 2662-2669.

(36) Hummers, W. S.; Offeman, R. E. Preparation of Graphitic Oxide. J. Am. Chem. Soc. 1958, 80, 1339-1339.

(37) Zhang, H. Y.; Miao, A. J.; Jiang, M. Fabrication, Characterization and Electrochemistry of Organic-Inorganic Multilayer Films Containing Polyoxometalate and Polyviologen Via Layer-by-Layer SelfAssembly. Mater. Chem. Phys. 2013, 141, 482-487.

(38) Creaser, I.; Heckel, M. C.; Neitz, R. J.; Pope, M. T. Rigid Nonlabile Polyoxometalate Cryptates $\left[\mathrm{ZP}_{5} \mathrm{~W}_{30} \mathrm{O}_{110}\right]^{(15-\mathrm{N})-}$ That Exhibit 
Unprecedented Selectivity for Certain Lanthanide and Other Multivalent Cations. Inorg. Chem. 1993, 32, 1573-1578.

(39) Yamase, T. Photo- and Electrochromism of Polyoxometalates and Related Materials. Chem. Rev. 1998, 98, 307-325.

(40) Li, J.; Tang, W.; Yang, H.; Dong, Z.; Huang, J.; Li, S.; Wang, J.; Jin, J.; Ma, J. Enhanced-Electrocatalytic Activity of $\mathrm{Ni}_{1-\mathrm{X}} \mathrm{Fe}_{\mathrm{x}}$ Alloy Supported on Polyethyleneimine Functionalized $\mathrm{MoS}_{2}$ Nanosheets for Hydrazine Oxidation. RSC Adv. 2014, 4, 1988-1995.

(41) Strbac, S. The Effect of $\mathrm{pH}$ on Oxygen and Hydrogen Peroxide Reduction on Polycrystalline Pt Electrode. Electrochim. Acta 2011, 56, $1597-1604$.

(42) Feng, Y.; He, T.; Alonso-Vante, N. Oxygen Reduction Reaction on Carbon-Supported $\mathrm{CoSe}_{2}$ Nanoparticles in an Acidic Medium. Electrochim. Acta 2009, 54, 5252-5256. 